\title{
... TIPS
}

It seems extreme sometimes to start a list with such a decisive \# 1. With working on a painting too, instead of expecting where you are exploring to arrive at GREAT results, have a longer term faith and expectation that your process will bear fruit and lead toward stronger paintings (and paintings with more inherent direction). Sometimes a painting is more of a stepping stone than a destination to arrive at. Sometimes there are different cues for leaving a piece and moving on to something new. Imagine running toward a park bench to jump upon it and spring up to grab a branch of a tree to climb into. Sometimes the painting you are working on is like the park bench. If you continue to focus too long on the bench then you will lose the momentum for achieving the greater sequence of events. Studies and "unfinished" pieces can be beautiful and useful; knowing their place allows one to use a primed energy for something next that is coming in the right place at the right time. Consider Guernica by Picasso, look at all of the preparatory drawings and twists of direction.

2. With \#2 comes practicing a second perspective, alternative perspectives. Practice this in the studio and out. Find different ways of looking, perceiving, and experiencing. Alter the lighting in the studio. Meditate on your painting in near dark, allow elements to converge and see them differently, with the larger components being showcased more tangibly. Look in a mirror to study a reversed image. Know when to leave a painting and come back to it to see with fresh eyes. Don't always jump in these breaks to checking your phone or the same patterns of conversation with classmates. Go for a quick walk in nature, practice being alone, meditate, look at images that are not a part of your regular routine. If you are working on something representative/figurative, try to see it as a flat collection of purely abstract shapes and consider broader and more open alternatives. Don't be a slave to your reference material. Don't be afraid to alter elements for a higher synthesis.

Threee. Allow your paintings to speak to you as much as you always try to guide the process. BE RECEPTIVE. Practice meditation. Practice putting down your brushes and palette knives and reference material and just sit back and watch. Look at your painting with the expectation of not at all trying to figure anything out. Without at all trying to know what to do next. Just be in the moment and see things as they are now. Some small 
cue may appear, but don't expect it to. Small cues are often appearing, but we are too coarse to pick them up much of the time. Becoming more open will allow more of a collaborative process to begin taking shape between you and your paintings. Perhaps this is representative of more of a collaborative process beginning to take shape between more conscious elements of yourself with more unconscious elements of yourself. What is happening here doesn't matter as much as allowing it to happen.

4. Have fun! If you are never having fun then it will show in your body of work. If you are not enjoying yourself and are wrapped up in your process, then you will not be riding the edge of your response system in the painting process. Your reaction impulses will be dulled down and you will be vastly decreasing the frequency of those surprising synchronistic brush strokes, serendipitous accidents, and oddly working combinations.

5. Keep your prices consistent, show them for the same pricing whether you are getting the full sale, splitting it half n' half with a gallery, or any other combination. Build a value for your paintings. Build a value for your work. Believe in yourself.

Geoff Farnsworth

http://www.geoff-farnsworth.com 